\title{
Breast cancer surveillance: nothing has changed in the past decades (?)
}

\author{
Zsuzsanna Kahán
}

Received: 2 January 2014 / Accepted: 20 February 2014 / Published online: 28 February 2014

(C) Springer-Verlag Wien 2014

\begin{abstract}
In the well-developed countries, breast cancer-related mortality rates show decreasing tendency. Relapse occurs only in about one-fourth of all patients. According to randomized studies, no survival benefit is provided in these cases by practising intensive followup including instrumental studies to actively search for distant metastases. The most important role of patient surveillance is to detect early-stage, potentially curable isolated local/regional relapses or second primary breast cancers. More and more attention is given to the early detection and treatment of the side-effects of the therapy on the other hand. Even a "minimalist" followup practice maintains the relationship with the patient that is important for getting reassurance for compliance with adjuvant endocrine therapies, assistance in case of symptoms of metastasis, or if medical or social decisions are to be made. Sometimes psychological problems occur, which necesitate special support. In routine practice, regular visits including patient history, physical examination, and breast imaging studies on a 6-12 monthly basis for up to 5 years and yearly thereafter with the maintenance of a supportive relationship with the patient are recommended. Chest, abdominal or bone imaging studies, laboratory or tumor marker tests are justified only in suspicion of relapse.
\end{abstract}

Keywords Breast cancer · Follow-up · Local relapse · Metastases · Side-effects

Z. Kahán, MD, DSc $(\bowtie)$

Department of Oncotherapy, University of Szeged,

Korányi fasor 12, Szeged 6720, Hungary

e-mail: kahan.zsuzsanna@med.u-szeged.hu

\section{Introduction}

The practice of follow-up of breast cancer patients is still inconsistent after the completion of hospital-based treatments (surgery, chemotherapy, and radiotherapy). Despite the fact that solid, evidence-based guidelines exist for the rational surveillance of breast cancer patients after the curative-intent adjuvant therapy [1-3], some physicians still favor performing intensive follow-up utilizing instrumental studies with the aim of early detection of distant metastases. Nowadays, about half of the breast cancers are mammography screening-detected, which predicts an excellent outcome with cure in more than $90 \%$ of the cases. Thanks to increasing breast cancer awareness, even non-screen detected cancers are diagnosed at a relatively earlier stage than before, and the efficiency of adjuvant treatments is ever improving. Thus, in the well-developed countries, relapse rates and breast cancer-related mortality are decreasing. On the other hand, the mechanism of development, detection, and therapy of the treatment side-effects in both the short-term (endocrine therapies) and long-term (radiotherapy) are more and more well understood, prevented, or treated, just as the psychological burden related to the disease and treatments. While keeping in mind ethical issues, the best utilization of financial resources must be also an issue when the optimum follow-up practice is to be defined.

One of the most important roles of follow-up after the primary treatment of operable breast cancer is the early detection of potentially curable isolated local/ regional relapse or a second primary breast cancer, and the other is the detection of the side-effects of the therapy on the other hand. Even a "minimalist" follow-up practice maintains the relationship with the patient that is important for getting reassurance for compliance with adjuvant endocrine therapy, assistance in case of symptoms of metastasis, or if medical or social decisions are 
Table 1 The goals of follow-up of patients after hospitalbased treatments

\begin{tabular}{l|l|}
$\begin{array}{l}\text { Monitoring cancer relapse } \\
\text { or second primary }\end{array}$ & $\begin{array}{l}\text { Monitor for local/regional relapse } \\
\text { Monitor for signs or symptoms of metastasis } \\
\text { Monitor for second primary breast cancer }\end{array}$ \\
\hline $\begin{array}{l}\text { Maintenance of } \\
\text { compliance with therapy } \\
\text { and management of } \\
\text { side-effects }\end{array}$ & $\begin{array}{l}\text { Monitor for side-effects of ongoing therapy } \\
\text { and patient reassurance }\end{array}$ \\
\hline $\begin{array}{l}\text { Monitor, counsel and manage for side-effects } \\
\text { of already completed therapies }\end{array}$ \\
\hline $\begin{array}{l}\text { Psychosocial support } \\
\text { Breast cosmesis }\end{array}$ \\
\hline Childbearing issues \\
\hline Social decisions \\
\hline Genetic counseling
\end{tabular}

to be made [4]. Sometimes psychological problems occur which necessitate special support (Table 1).

\section{Intensive versus "rational" surveillance}

Four randomized studies and a meta-analysis provide solid basis and consistent evidence in favor of practising a simple clinical follow-up confined to clinical visit and mammography, and against instrumental tests to detect distant metastases. In the first study, including a cohort of 1,243 patients, although, the patients on the intensive follow-up arm were diagnosed earlier with metastases, no survival benefit occurred between the arms [5], even if the survival analysis was extended to 10 years [6]. A similar trial enrolling 1,320 patients gave identical results after a follow-up time of 71 months [7]. Health-related quality of life did not differ either according to the method of follow-up. A third randomized study including 296 patients, indicated that most tumor recurrences were interval events detected between the regular visits, independent of having been followed-up in an intensive or "minimalist" way. No significant difference was detected in most of the quality of life dimensions among the groups [8]. Kokko et al. [9], studied both the type and timing of surveillance on survival and costs. The conclusion was that neither the frequency of the visits nor its intensity had any effect on the survival of patients. Intensive follow-up increase the costs of follow-up 2.2 times [9]. The data of the first three studies were investigated in the Cochrane Database, the pooled data analysis confirmed that no survival advantage is provided by an intensive follow-up approach, and survival is similar among the subgroups according to age or risk indicators [10].

In an early study, Winchester et al. [11] analyzed the time of metastasis detection in 87 patients with disseminated disease. Most of the patients had symptoms that necessitated staging examinations, and only in three cases was the imaging study or laboratory finding the one that revealed the distant metastasis [11]. Furthermore, since diagnostic tests in asymptomatic patients often provide ambiguous or false-positive results, further sophisticated examinations might be needed that easily raise anxiety in the patient [12-14].

Obviously, a "minimalist" follow-up program is less expensive than its intensive counterpart [9], and practice non-compliant with guidelines needs 2.2-3.6 times greater resources [15]. According to the study of Gulliford et al. [16], average-risk patients prefer less frequent follow-up, and equally cooperate with routine or intensive surveillance $[4,17]$.

\section{Monitoring local/regional relapse and second primary breast cancer}

The incidence of local or regional relapses depends on the patient population and the quality of the primary care, but, in general is well below $10 \%$. Local or regional relapses most often occur during the first 3-5 years after surgery. One out of four local relapses cause the death of the patient [18]. The risk of local or regional relapse after the primary management, varies according to the mode of detection, the mammographic appearance, the tumor size, the histological type (triple negative and HER2positive tumors!), the presence of extensive intraductal component and the distribution of the lesion (multifocality, diffuse lesions!), the surgical margin status, the type of lymph node surgery and the nodal status, the age of the patient (young age especially in DCIS!), the use and quality of radiotherapy and systemic therapy [19-21]. The incidence of metachronous second breast cancer (in the opposite breast, or in the operated breast outside of the primary tumor's location) is $0.5-1.0 \%$ per subsequent year, the odds ratio of developing it after the first breast cancer is about 1.25. Both local relapses and second primary breast cancers may be well controlled if the tumor is detected at a small size. Therefore, careful, preferably risk-adapted monitoring is suggested. Breast imaging of the operated breast should be examined by ultrasound and mammography every 6-12 months for 2 years, and yearly thereafter, while the opposite breast yearly. In dubious cases, complex clinical breast examination is needed to clarify the diagnosis.

\section{Monitoring side-effects of therapy}

\section{Local therapy}

Surgery itself may cause numbness, pain, and/or swelling of the breast or the arm. Radiotherapy is widely practised; however, radiogenic side-effects are relatively rare. Few months after the radiotherapy radiogenic pneumonitis and later on localized pulmonary fibrosis of the lung may occur $[19,22]$. Radiogenic hypothyreosis is rare, but should be diagnosed by the symptoms. The fibrosis of the soft tissues may cause breast pain and worsen cosmetic outcome, or may contribute to the lymphedema of the arm $[19,23]$. In the long-term, the development of ischemic heart disease due to the damage of the left anterior 
descending coronary artery $[19,24,25]$, or radiogenic second cancers may occur [26]. Alertness during followup is essential since specific therapy or intervention may control the abnormality.

\section{Systemic therapy}

During the follow-up period, chronic or late side-effects of chemotherapy are relevant. Thus, symptoms due to premature menopause, fatigue, cognitive dysfunction ("chemo brain"), osteoporosis, rarely cardiac dysfunction (to which Herceptin therapy may contribute to) or secondary malignancies occur [4]. The adverse effects of endocrine therapies include genitourinary problems and sexual dysfunction, weight gain, osteoporosis, arthralgia, effects on the nervous system and cognitive dysfunction, thus deteriorating health-related quality of life [4, 27]. Some long-term, even definitive side-effects may be the consequence of both chemotherapy and endocrine therapy.

Patients after chemotherapy/Herceptin therapy may need cardiac surveillance if cardiac dysfunction has been detected during the treatment or if suspected by specific symptoms. Osteoporosis should be monitored and treated in patients with early premenopause or on aromatase inhibitor therapy. Tamoxifen therapy increases the risk of thromboembolic events, endometrial hyperplasia/cancer, stroke, and cataract formation. Those who complain about musculoskeletal problems should be admitted to physiotherapist. Various gynecological problems may be ameliorated with hormonal or nonhormonal interventions. Fatigue may be controlled with special training or relaxation techniques.

\section{Fertility issues}

Some patients may wish to bear children after primary management of breast cancer $[4,28]$. They intend to know the potential to get pregnant, and whether pregnancy may deteriorate their prognosis. Also, the possible teratogenic effect of the previous chemotherapy on the fetus is a concern. These issues should be carefully and openly discussed and managed with the patient and her gynecologist. At present, there is no evidence for the adverse effect of pregnancy on the underlying disease, however, only restrospective analyses have been performed [4, 28]. Breast feeding may be possible even after breast-conserving surgery and postoperative radiotherapy in less than half of the patients; in the others, unilateral lactation may be sufficient [28].

\section{Psychosocial support}

The diagnosis of breast cancer and its treatment may induce anxiety, depression, and problems with physical, social and sexual functioning that adversely affect quality of life. The majority of patients report satisfying functioning after the completion of chemotherapy and easily return to normal life. Occasionally, patients may need the help of the physician performing the follow-up, or the assistance of a psychologist or psychiatrist.

\section{Genetic counseling}

Some of the women request or need genetic counseling for learning their inherited risk for familial breast cancer syndromes. These patients should be referred to genetic tests if consented after discussing the risks and benefits. Clinical guidelines recommend referral in the following situations $[1,29]$ :

1. Ashkenazi Jewish heritage

2. History of ovarian cancer at any age in the patient or any first- or second-degree relatives

3. Any first-degree relative with a history of breast cancer diagnosed before the age of 50

4. Two or more first- or second-degree relatives diagnosed with breast cancer at any age

5. Patient or relative with diagnosis of bilateral breast cancer

6. History of breast cancer in a male relative.

\section{Post scriptum}

New developments in oncology may make a significant impact on the natural course of the disease. The discovery of the platinum agents' effects on testicular cancer was the first in line that caused a change never ever seen before in advanced solid tumors. Then, the application of anti-HER2 therapies in HER2-positive breast cancer, the success of neoadjuvant chemotherapy in certain breast cancers, or the modern view and management practice of metastatic cancers such as colorectal cancer, to either perform metastasectomy and/or temper the disease to a chronic status amenable to be kept under control.

The rapidly developing era utilizing sophisticated diagnostic methods and individualized molecular targeted therapy might bring new possibilities in the management of metastatic breast cancer. If so, it may turn out, that in high-risk patients, the early detection of metastases would yield benefit in terms of possible cure or the prolongation of survival. At present, however, yet no such perspectives are apparent, thus follow-up should be restricted to evidence-based guidelines (Table 2). The surveillance of patients may be equally efficiently performed by specialists (surgeons, oncologists, and radiotherapists), general practitioners, or even trained nurses adherent to guidelines; follow-up practice should be organized according to resources, traditions, or other factors $[1,30]$. 
Table 2 Recommendations for breast cancer follow-up and management in the adjuvant setting. (Based on the Practice Guidelines of the American Society of Clinical Oncology, 2013 [1])

\begin{tabular}{|l|l|l|}
\hline $\begin{array}{l}\text { Recom- } \\
\text { mended }\end{array}$ & Hest & Frequency \\
\hline & Breast self-examination (patient) & $\begin{array}{l}\text { Every 3-6 months up to } \\
\text { 3 years, then every 6-12 } \\
\text { months for 2 years, and } \\
\text { yearly thereafter }\end{array}$ \\
\hline Mammography & $\begin{array}{l}\text { Monthly } \\
\text { Every 6-12 months; } \\
\text { yearly if mammographic } \\
\text { findings get stable }\end{array}$ \\
\hline & $\begin{array}{l}\text { Pelvic examination including a Pap } \\
\text { smear }\end{array}$ & $\begin{array}{l}\text { Regular gynecological } \\
\text { follow-up according to } \\
\text { risk }\end{array}$ \\
\hline & $\begin{array}{l}\text { Patient education regarding symp- } \\
\text { toms of recurrence and genetic } \\
\text { counseling }\end{array}$ & As needed \\
\hline $\begin{array}{l}\text { Rot } \\
\text { recom- } \\
\text { mended } \\
\text { chemistry studies, circulating tumor } \\
\text { markers: CA 15-3, CA 27.29, CEA) }\end{array}$ & $\begin{array}{l}\text { Imaging studies: chest X-rays, bone } \\
\text { scans, ultrasound of the liver, CT, } \\
\text { PET/CT, breast MRI }\end{array}$ \\
\hline $\begin{array}{l}\text { aTamoxifen therapy increases the risk of endometrial abnormalities, while } \\
\text { hysterectomy, oophorectomy represent reduced risk }\end{array}$ \\
\hline
\end{tabular}

\section{Take-home message}

Following the primary treatment of breast cancer, regular visits including physical examination, breast imaging studies on a 6-12 monthly basis for up to 5 years, and yearly thereafter, with the maintenance of a supportive relationship with the patient are recommended. Chest, abdominal or bone imaging studies, laboratory or tumor marker tests are justified only if tumor recurrence is suspected.

\section{Conflict of interest}

The author declares that she has no conflict of interest.

\section{References}

1. Khatcheressian JL, Hurley P, Bantug E, et al. American Society of Clinical Oncology. Breast cancer follow-up and management after primary treatment: American Society of Clinical Oncology clinical practice guideline update. J Clin Oncol. 2013;31:961-5.

2. Aebi S, Davidson T, Gruber G, Cardoso F. Primary breast cancer: ESMO clinical practice guidelines for diagnosis, treatment and follow-up. Ann Oncol. 2011;22 (suppl 6):vi12-24.

3. NCCN. 2013. http://www.nccn.org/professionals/physician_gls/f_guidelines.asp. version 1.2014 .

4. Partridge AH, Winer EP, Burstein HJ. Follow-up care of breast cancer survivors. Semin Oncol. 2003;30:817-25.
5. Rosselli Del Turco M, Palli D, Cariddi A, Ciatto S, Pacini P, Distante V. Intensive diagnostic follow-up after treatment of primary breast cancer. A randomized trial. National Research Council Project on Breast Cancer follow-up. JAMA. 1994;271:1593-7.

6. Palli D, Russo A, Saieva C, et al. Intensive vs clinical followup after treatment of primary breast cancer: 10-year update of a randomized trial. National Research Council Project on Breast Cancer Follow-up. JAMA. 1999;281:1586.

7. GIVIO. Impact of follow-up testing on survival and healthrelated quality oflife in breast cancer patients. A multicenter randomized controlled trial. JAMA. 1994;271:1587-92.

8. Grunfeld E, Mant D, Yudkin P, et al. Routine follow up of breast cancer in primary care: randomised trial. BMJ. 1996;313:665-9.

9. Kokko R, Hakama M, Holli K. Follow-up cost of breast cancer patients with localized disease after primary treatment: a randomized trial. Breast Cancer Res Treat. 2005;93:255-60.

10. Rojas MP, Telaro E, Russo A, Moschetti I, Coe L, Fossati R, et al. Follow-up strategies for women treated for early breast cancer. Cochrane Database Syst Rev. 2005:CD001768.

11. Winchester DP, Sener SF, Khandekar JD, et al. Symptomatology as an indicator of recurrent or metastatic breast cancer. Cancer. 1979;43:956-60.

12. Schapira DV, Urban N. A minimalist policy for breast cancer surveillance. JAMA. 1991;265:380-2.

13. Lee JE, Park SS, Han W, et al. The clinical use of staging bone scan in patients with breast carcinoma: reevaluation by the 2003 American Joint Committee on Cancer staging system. Cancer. 2005;104:499-503.

14. Harris L, Fritsche H, Mennel R, et al. American Society of Clinical Oncology. American Society of Clinical Oncology 2007 update of recommendations for the use of tumor markers in breast cancer. J Clin Oncol. 2007;25:5287-312.

15. Mille D, Roy T, Carrère MO, et al. Economic impact of harmonizing medical practices: compliance with clinical practice guidelines in the follow-up of breast cancer in a French Comprehensive Cancer Center. J Clin Oncol. 2000;18:1718-24.

16. Gulliford T, Opomu M, Wilson E, Hanham I, Epstein R. Popularity of less frequent follow up for breast cancer in randomised study: initial findings from the hotline study. BMJ. 1997;314:174-7.

17. Loprinzi CL, Hayes D, Smith T. Doc, shouldn't we be getting some tests? J Clin Oncol. 2000;18:2345-8.

18. Early Breast Cancer Trialists' Collaborative Group (EBCTCG), Darby S, McGale P, Correa C, et al. Effect of radiotherapy after breast-conserving surgery on 10-year recurrence and 15-year breast cancer death: meta-analysis of individual patient data for 10,801 women in 17 randomised trials. Lancet. 2011;378:1707-16.

19. Kahán Z, Hideghéty K, Varga Z. Breast cancer, a heterogeneous disease entity. The very early stages. Springer, Dordrecht; 2011. Chap. 10, the risks of radiotherapy, and how to avoid them. pp. 241-68.

20. Liljegren G, Lindgren A, Bergh J, et al. Risk factors for local recurrence after conservative treatment in stage I breast cancer. Definition of a subgroup not requiring radiotherapy. Ann Oncol. 1997;8:235-41.

21. Holmberg L, Wong YN, Tabár L, et al. Mammography casting-type calcification and risk of local recurrence in DCIS: analyses from a randomised study. Br J Cancer. 2013;108:812-9. 
22. Dorr W, Bertmann S, Herrmann T. Radiation induced lung reactions in breast cancer therapy. Modulating factors and consequential effects. Strahlenther Onkol. 2005;181:567-73.

23. Johansen J, Overgaard J, Rose C, et al. Cosmetic outcome and breast morbidity in breast-conserving treatment. Acta Oncol. 2002;41:369-80.

24. Darby SC, Cutter DJ, Boerma M, et al. Radiation-related heart disease: current knowledge and future prospects. Int J Radiat Oncol Biol Phys. 2010;76:656-65.

25. Darby S, McGale P, Taylor CW, Peto R. Long-term mortality from heart disease and lung cancer after radiotherapy for early breast cancer: prospective cohort study of about 300000 women in US SEER cancer registries. Lancet Oncol. 2005;6:557-65.

26. Cuzick J, Stewart H, Rutqvist L, et al. Cause-specific mortality in long-term survivors of breast cancer who participated in trials of radiotherapy. J Clin Oncol. 1994;12:447-53.
27. Kahán Z. Breast cancer, a heterogeneous disease entity. The very early stages. Springer, Dordrecht; 2011. Chap. 12, systemic therapy: selection of patients. Endocrine therapy. pp. 283-304.

28. Pagani O, Partridge A, Korde L, et al. Breast International Group; North American Breast Cancer Group Endocrine Working Group. Pregnancy after breast cancer: if you wish, ma'am. Breast Cancer Res Treat. 2011;129:309-17.

29. Balmaña J, Díez O, Rubio IT, Cardoso F, ESMO Guidelines Working Group. BRCA in breast cancer: ESMO Clinical Practice Guidelines. Ann Oncol. 2011;22 (Suppl 6):vi31-4. doi:10.1093/annonc/mdr373.

30. Kwast AB, Drossaert CH, Siesling S; follow-up working group. Breast cancer follow-up: from the perspective of health professionals and patients. Eur J Cancer Care (Engl). 2013;22:754-64. 